\title{
Male Breast Cancer-Dosimetry Evaluation in Teletherapy
}

\author{
Nilmara A. Guimarães*, Verginia R. Crispim \\ Universidade Federal do Rio de Janeiro, UFRJ/CT/COPPE/Programa de Engenharia Nuclear, Rio de Janeiro, \\ Brazil \\ Email: "nilaguimaraes@hotmail.com
}

Received 25 August 2014; revised 24 September 2014; accepted 22 October 2014

Copyright $@ 2014$ by authors and Scientific Research Publishing Inc.

This work is licensed under the Creative Commons Attribution International License (CC BY).

http://creativecommons.org/licenses/by/4.0/

(c) (i) Open Access

\section{Abstract}

The rate of male breast cancer has increased in recent years, due to the deficiency of preventive examinations (male mammography). Besides, since male breasts are generally smaller than female breasts, it is essential to monitor the doses received by male breasts, as well as those received by close, healthy and critical organs in order to assess the plan used in this kind of treatment. To do this, the distribution of doses in male breasts was simulated and assessed, based on the procedures adopted in the treatment of female breasts, when submitted to a radiation beam from a linear accelerator. The Alderson Rando phantom was used and the relevant absorbed doses were measured by TLD-100 thermoluminescent dosimeters distributed throughout the volume of interest. The results of the treatment planning were compared with the results obtained by TLDs. A difference of up to $8.5 \%$, in comparison with the planned dose, as well as a $6 \%$ relative standard deviation was found.

\section{Keywords}

Radiotherapy, Dosimetry, Absorbed Dose, Teletherapy, Metrology

\section{Introduction}

The second most lethal cancer in the world is breast cancer, which can also affect men [1] [2] and which, as more unusual, is not much studied. It represents about $1 \%$ of all breast cancers, accounting for less than $0.1 \%$ of deaths in men [3] [4].

Cancer may be treated in various ways, through: surgery, chemotherapy, radiotherapy or a combination thereof. In the absence of proper protocols, the recommended treatment for male breast cancer follows the treat-

"Corresponding author.

How to cite this paper: Guimarães, N.A. and Crispim, V.R. (2014) Male Breast Cancer-Dosimetry Evaluation in Teletherapy. International Journal of Medical Physics, Clinical Engineering and Radiation Oncology, 3, 241-251. 
ment established for female breast cancer, based on surgical treatment, combined or not with radiotherapy, chemotherapy, and especially hormonal therapy [5]. Since the structure and volume of male breasts may be different from those of female breasts, radiotherapy must also be different in terms of distributed doses.

\subsection{Radiotherapy through Teletherapy}

In teletherapy, the radiation issued by the applicable device is targeted at the body region to be treated, while patient is lying down, and sessions are performed daily. Cobalt therapy machines $\left({ }^{60} \mathrm{Co}\right)$ and linear accelerators are the equipment used.

\subsection{Dose Distribution}

The distribution of doses refers to the dose values at points surrounding and inside the irradiated volume. In radiotherapy, a detailed analysis of the dose distribution allows drawing conclusions with respect to the preservation of healthy tissues near the target volume. Thus, it is important to make sure that the doses prescribed by physicians focus on the target volumes, so that healthy tissues do not receive doses beyond the tolerance limits recommended in literature.

\subsection{Ionizing Radiation Dosimeters}

The result of measurement is a dosimetric amount expressed by a number associated with its unit. There are several types of radiation dosimeters, but not all meet the necessary requirements for the intended application. Thus, it is necessary to choose the most appropriate one, taking into account the requirements of the measurement situation. Among the types of dosimeters on the market, we shall highlight: ionization chamber, radiographic film, radiochromic film, thermoluminescent dosimeter (TLD) and semiconductors (diode) [6].

\subsection{Thermoluminescent Dosimeter}

The thermoluminescent dosimeter is a device that measures doses resulting from the thermoluminescence phenomena, which occurs when there is light emission after the excitation of a material medium by thermal energy. Light emission may result by fluorescence, when light emission occurs spontaneously, and by phosphorescence, when it is necessary to apply energy for it to be seen. TL dosimeters can be found in various shapes and compositions, as shown in Figure 1.

Among the main TL dosimeters, we shall highlight: LiF: Mg, Ti; $\mathrm{CaF}_{2}$ : Dy; CaSO4: Dy; $\mathrm{CaF}_{2}$ : Mn; LiF: Mg, $\mathrm{P}, \mathrm{Cu}$; and $\mathrm{Li}_{2} \mathrm{~B}_{4} \mathrm{O}_{7}$ : Mn. The chip dosimeter, composed of lithium fluoride, is generally the most widely used in dosimetry, as it is easily manipulated, and presents good repeatability and reproducibility conditions.

\section{Materials and Methods}

To characterize and calibrate TLD thermoluminescent dosimeters, irradiations were performed at a known dose rate in the teletherapy equipment ONCOR Expression, manufactured by SIEMENS, installed at COI (for the acronym in Portuguese for Integrated Oncology Centers). The accelerator used in the characterization was the

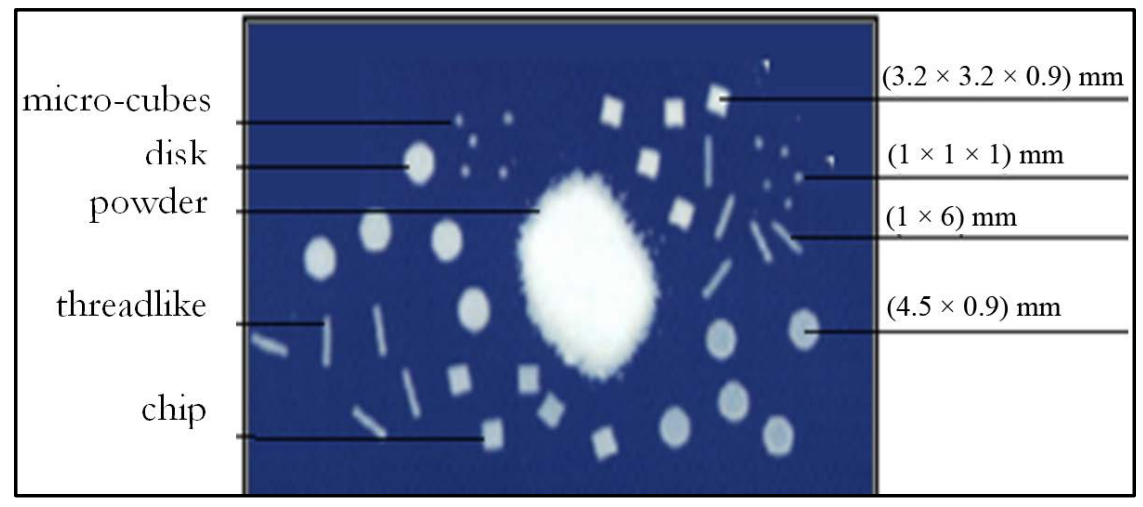

Figure 1. Types of thermoluminescent dosimeters (Taken from [7]). 
same used for irradiation, namely, a $6.0 \mathrm{mV}$ photon beam and, therefore, it was not necessary to determine the energy dependence factor.

The thermoluminescent dosimeters used were TLD-100 (LiF: Mg, Ti), in the shape of chip, measuring $3.2 \mathrm{~mm} \times 3.2 \mathrm{~mm} \times$ $0.9 \mathrm{~mm}$, manufactured by Thermo Fischer Scientific Inc., commercially known as Harshaw TLD (Figure 2).

For proper use of TLDs, it was necessary to determine their individual characteristics. Among the group of TLDs, those which met the characteristics identified by the manufacturer were identified, and the relevant provided quality controls were obtained through sampling.

The steps followed for the selection of chips suitable for dose measurements require knowledge of each chip specifically and include:

Univocal identification of TLD;

Thermal pre-treatment;

Response "Zero", corresponding to the condition “not irradiated”, also known as "BG” level (background);

Evaluation of sensitivity;

Evaluation of linearity according to calibration;

Assessment of other correction factors: time, transportation and energy dependence, which were not necessary in this case.

Since TLDs were not brand new, after being identified, they were heat treated at $400^{\circ} \mathrm{C}$ for one hour, and at $100^{\circ} \mathrm{C}$, for two hours, in order to remove any residual dose previously applied.

\subsection{Stacking and Reading of TLDs}

After the initial heat treatment, these TLDs were inserted in coupelles to be read, organized in a predefined reading order and stacked with the assistance of a lift. A twelve hour interval to perform new radiations was taken into account. Once stacked, so that measures found in each TLD could be tracked, they were placed in a Fimel PCL3 reader. As such, the BG values of the 200 TLDs examined were determined. The mean reading of the "zero dose" $\left(\mathrm{TL}_{0}\right)$ was obtained through the mean of the readings of the 200 TLDs by Equation (1). The measurement uncertainty associated with this parameter was the standard deviation of the 200 readings.

$$
\mathrm{TL}_{0}=\sum_{I=0}^{200} \mathrm{TL}_{0}
$$

The reader's charger was able to stack up to 93 coupelles, or 93 chips (TLDs). The reader had a system which included a rotating disk and tweezers that removed every coupelle from the charger and took it to oven no. 1, to oven no. 2, to the photomultiplier valve and, finally, placed it in a disposal charger. In oven no. 1, the coupelle was submitted to a temperature of $170^{\circ} \mathrm{C}$ for about 25 seconds and, in oven no. 2, to a temperature of $300^{\circ} \mathrm{C}$ for about 25 seconds. At this point, the photomultiplier valve recorded the light photons resulting from the release of electrons that were caught up in the TLDs' traps.

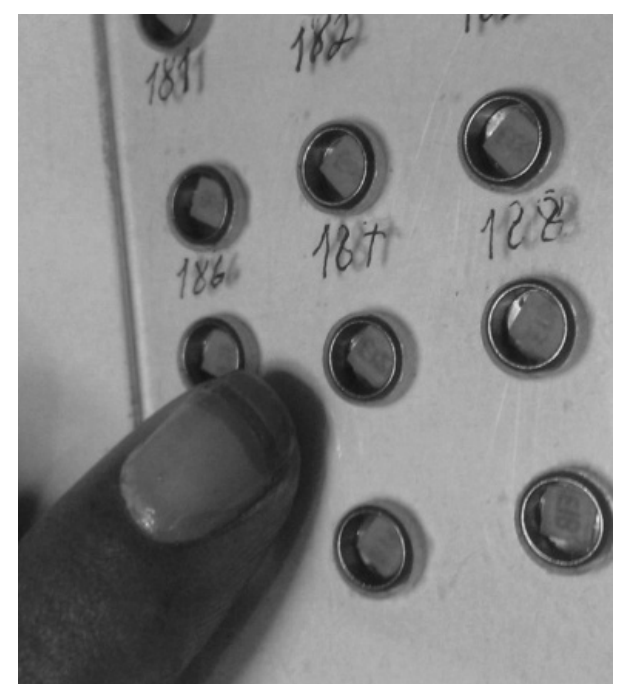

Figure 2. TLD-100 within the coupelle. 


\subsection{Evaluation of Sensitivity}

To determine the relative sensitivity of TLDs, the homogeneity of the field was ensured, by irradiating them at the same time, between solid water plates, as illustrated in Figure 3. A distance of $100 \mathrm{~cm}$ between the source and the plate surface was established, together with a $20 \mathrm{~cm} \times 20 \mathrm{~cm}$ irradiation field and a reference dose of 1 Gy.

The relative sensitivity of each TLD is defined by Equation (2), where: $N$ is the number of evaluated TLDs; $k$ is the number of irradiations performed; and $\mathrm{TL}_{i}, k$ is the reading of each TLD, after deducting the corresponding $\mathrm{BG}$.

$$
S_{i, k}=\frac{\mathrm{TL}_{i, k}}{\frac{1}{N} \sum_{i=1}^{N} \mathrm{TL}_{i, k}}
$$

\subsection{Evaluation of Linearity}

To evaluate the linearity, the 200 TLDs were divided into 10 batches initially identified by letters, and each batch received the following doses: (10, 50, 100, 150, 200, 250, 300, 350, 400 and 500) cGy. Each batch was irradiated three times and the dose-response relation (RDS) was calculated for each batch.

Using the Excel program, a graph of the Linearity Factor, $F_{\text {lin }}$, versus the dose received for each batch, was generated with the correction of the readings of TLDs, in relation to response linearity. After completion of the characterization stage, TLDs were distributed throughout the Alderson Rando phantom, where the male breast and critical organs could be found in slices 13 to 20 .

\subsection{Anthropomorphic Simulators or Phantoms}

Among the anthropomorphic phantoms used to reproduce the scattering and absorption characteristics of the body or body parts, when subjected to a radiation field, the best known is the Alderson Rando phantom (Figure 4) which consists of a skeleton covered with materials equivalent to tissues, lungs and soft tissues, and which follows the ICRU-44 standards [8].

This phantom is $175 \mathrm{~cm}$ tall and weighs $73.5 \mathrm{~kg}$, being transected-horizontally into $2.5 \mathrm{~cm}$ thick slices. Each slice has holes which are plugged with tissue equivalent pins which can be equivalent to: bones, soft-tissues or lungs. Such pins may be replaced by powder or chip TLD pins. TLDs were placed throughout the left side of the phantom between slices 13 and 20, as per Figure 5, where 5 mm-diameter holes with TLDs can be found in 3 $\mathrm{cm} \times 3 \mathrm{~cm}$ matrix.

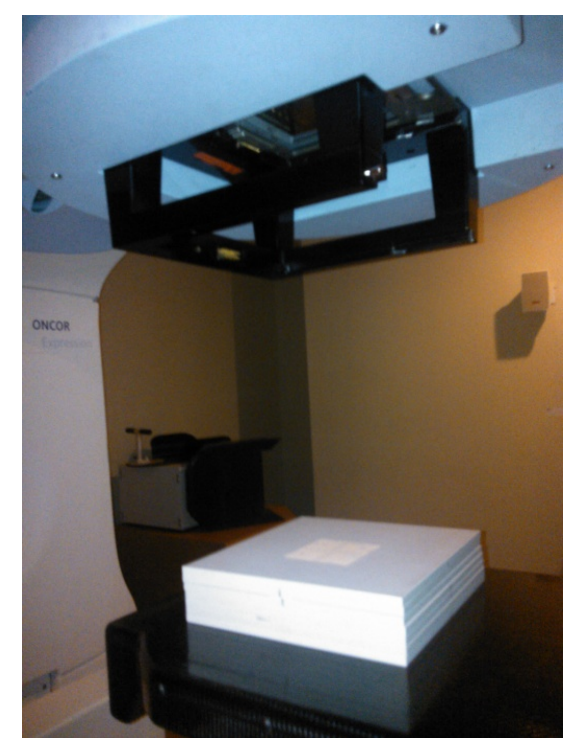

Figure 3. Experimental arrangement for the characterization of TLDs using a solid plate. 


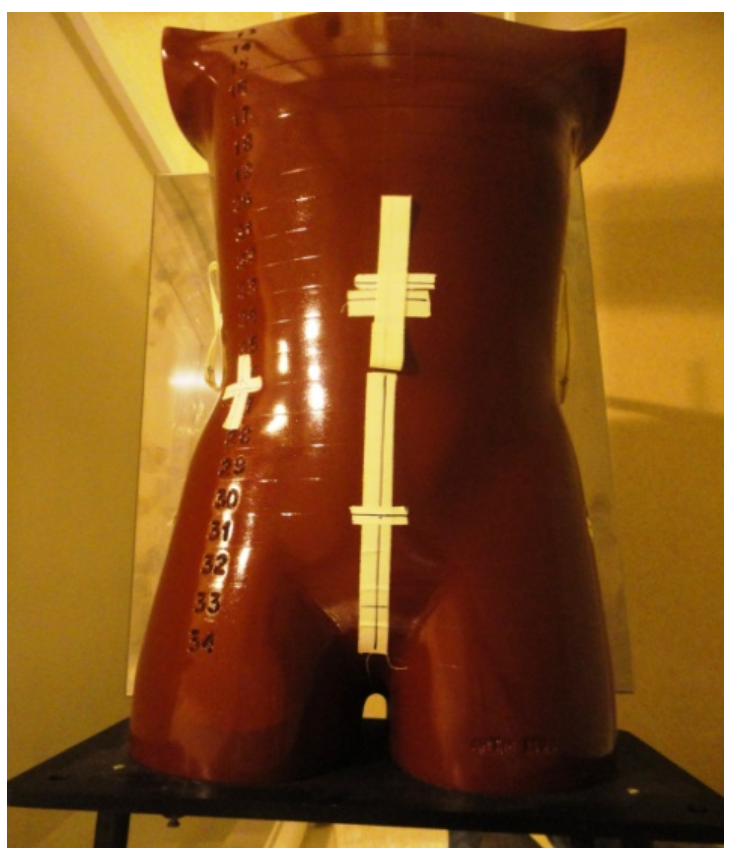

Figure 4. Alderson Rando phantom.

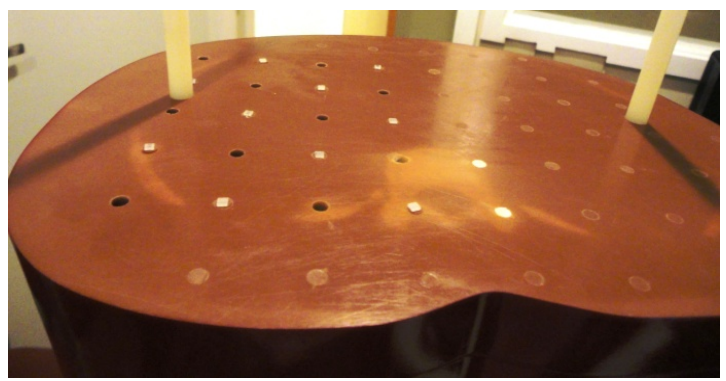

Figure 5. Slice with TLDs and holes [9].

\subsection{Male Breast Cancer Planning System}

The planning system used to simulate the treatment of male breast cancer, following protocols for treatment of female breast cancer, was Prowess, Version 5.11, which is available at COI. Prowess has an algorithm that can manage information about doses, monitor units, image acquisition and fusion, as well as transport planning directly to the linear accelerator in which treatment shall occur.

Planning was done with the images of the Alderson Rando phantom taken by a Siemens Emotion Duo CT scanner installed at COI. The treatment consisted in the irradiation of two opposing parallel fields with the prescription of 200 cGy at $100 \%$ of the isodose line. During the first stage of irradiation, the head, also known as gantry was at $303^{\circ}$, with a SSD (source-surface distance) of $88.1 \mathrm{~cm}$, a field of $10 \mathrm{~cm} \times 12 \mathrm{~cm}$ and a $240.7 \mathrm{MU}$ monitor unit with $30^{\circ}$ filter. In the second stage, the gantry rotated automatically to $123^{\circ}$, with a SSD of $88.5 \mathrm{~cm}$, a field of $10 \mathrm{~cm} \times 11 \mathrm{~cm}$ and a $241.8 \mathrm{MU}$ monitor unit, using the same filter.

For purposes of comparing the planned results with the ones obtained by TLDs, it was necessary to incorporate, in the planning system, some points of interest, i.e., specific TLD location, as shown in Figure 6. Thus, it was possible to generate a report where the doses planned were determined, at the points of interest.

\section{Results and Discussion}

\subsection{Sensitivity of TLDs}

After determining the relative sensitivity of each TLD, we found 64 TLDs which repeatability was of up to $\pm 0.5 \%$ 


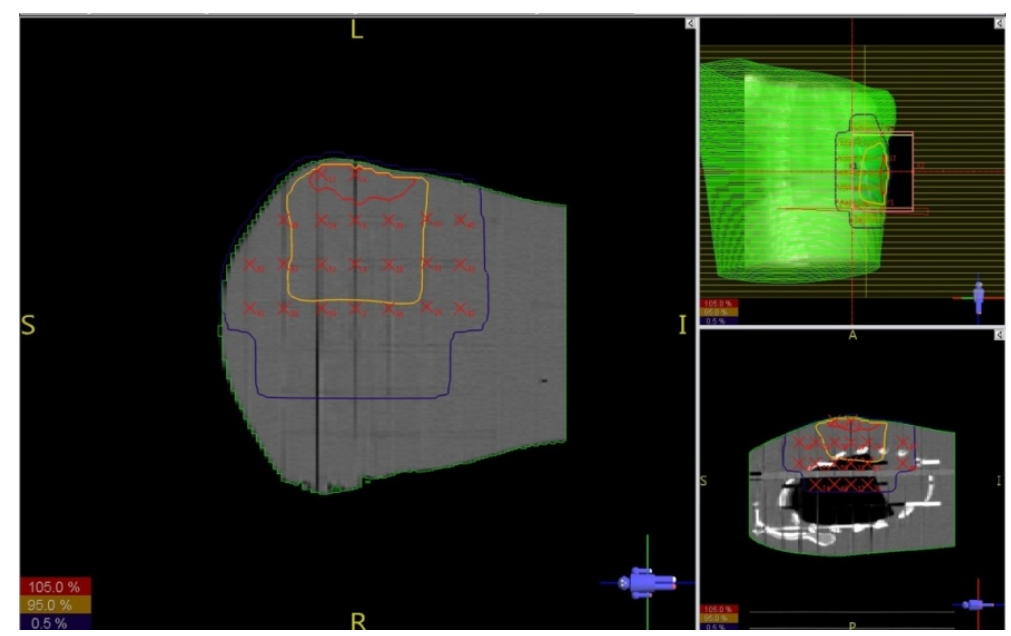

Figure 6. Prowess' Graphical Screen with the points of interest, near the male breast, located in the slices of the Alderson Rando phantom.

of standard deviation of the mean, 155 TLDs with up to $\pm 1 \%$ of standard deviation of the mean, 197 TLDs with up to $\pm 2 \%$ of standard deviation of the mean and three dosimeters which average standard deviation was above $3 \%$, within the specifications of the manufacturer.

The 155 dosimeters that showed standard deviations of the mean of up to $\pm 1 \%$ were selected for measurements.

\subsection{Linearity of TLDs}

To determine the response of TLDs, as a function of linearity with respect to dose, a dose range between 50 cGy and 500 cGy was taken into account. The ratio between delivered dose and TLD response was calculated for each dose chosen within the range of creation of the calibration curve. This ratio was normalized in relation to the $1 \mathrm{~Gy}$ reference dose, then obtaining the $F_{\text {lin }}$ factor, as to know, the correction factor for the non-linearity of reading presented by TLD irradiated with the unknown dose.

Figure 7 shows the calibration curve obtained with the Excel program for $F_{\text {lin }}$.

The R-squared value found was of 0.988 , which expresses how much error can be assumed by using the adjustment equation. R2 values close to 1.00 show a good quality of point adjustment to the curve and values below 0.8 indicate poor quality. It is important to note that this adjustment often introduces a doubt in $F_{\text {lin }}$, which can be minimized with the determination of the uncertainty due to adjustment through Equation (3). Such uncertainty must be expanded and, then, combined with the measurement uncertainty. The calculation of adjustment uncertainty will be determined by Equation (3).

$$
U_{\text {ajuste }}=K \cdot \sqrt{\frac{1}{n-2} \sum\left(y_{i}-y_{f\left(x_{i}\right)}\right)^{2}}
$$

where:

$U_{\text {ajuste }}$ is the uncertainty of the adjustment by the equation;

$K$ is the coverage factor, taken from the $t$-student table for $n-2$ degrees of freedom;

$n$ is the number of points used to generate the equation;

$y_{i}$ is the value of the error in the $i^{\text {th }}$-calibrated point, used to generate the equation of linearity;

$y_{f\left(x_{i}\right)}$ is the value of the error in the $i^{\text {th }}$-calibrated point, calculated by the linear equation.

The value found for $U_{\text {ajuste }}$, in Equation (3), considering a 68\% reliability, referring to \pm 1 standard deviation, in a normal probability distribution, was $0.00015 \%$.

This calibration curve has a considerable error for doses below 50 cGy, however, it was the best calibration curve generated in relation to the adjustment between actual and calculated points. This low adjustment uncertainty implies that such evaluated point, in relation to others, does not impact the final result of the use of the calibration curve. Nevertheless, it is necessary to observe the results found in doses of less than 50 cGy. 


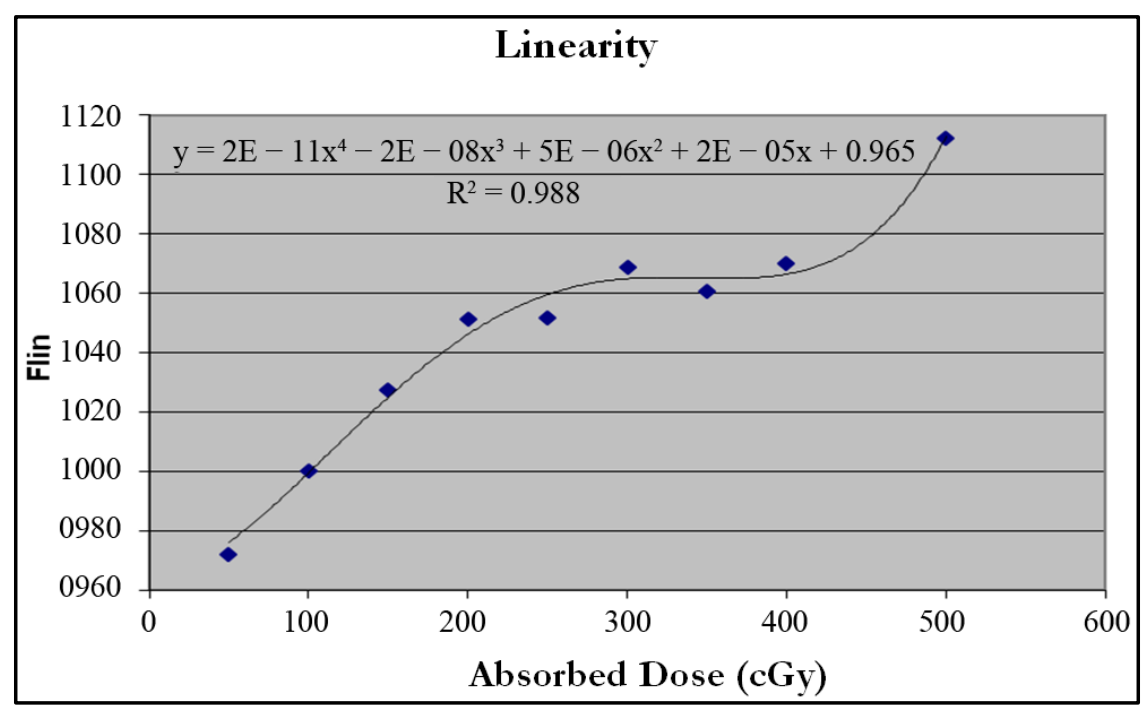

Figure 7. Curve for adjustment between TLDs’ Flin and doses.

\subsection{Measurement Uncertainties}

The uncertainty of the dose obtained by TLDs came from the analysis of input variables and resulted from the propagation of uncertainties, Equation (4):

$$
u_{D}^{2}=\left(\frac{\partial D}{\partial L}\right)^{2} u_{L}^{2}+\left(\frac{\partial D}{\partial S}\right)^{2} u_{S}^{2}+\left(\frac{\partial D}{\partial F_{\text {lin }}}\right)^{2} u_{F_{\text {lin }}}^{2}
$$

The relative uncertainty for dose $D$ experimentally obtained with TLDs was of $\pm 0.0114 \%$ or $\pm 1.14 \%$.

\subsection{Dosimetry with TLDs}

TLDs were scattered in the form of matrix on the right side of Rando Alderson on points presenting doses different from zero, within blue, yellow and red isodoses, from slice 15 to 18, as other slices showed no significant doses. TLDs were placed on pins that had a space for chip insertion.

Figures 8-11 show the distribution of TLDs in the phantom. Markings in red indicate TLDs inserted in the planning system. Points circled in white indicate the proper placement of TLDs, experimentally. In these figures, the area with higher reliability is the red one, followed by the yellow zone, and finally, by the blue zone, with the lowest reliability, based on the isodose curves assessed by the planning system.

Tables 1-4 show the comparison of absorbed and planned doses for each slice, where a relative standard deviation of up to $6 \%$ is observed.

Whereas the planning was done by placing the point of interest for the treatment of male breast cancer near TLD L01, located at position 10 of slice 16, the percentage error shown relative to the plan was of $0.3 \%$. That is, the planning coincides with the measurements expressed by TLDs, in the dose distribution for the treatment performed.

In Table 1, there is a difference of approximately 25 cGy for TLD plan number 63, however, the dose planned for this TLD was of 42.4 cGy and the calibration curve of TLDs is not reliable for measurements inferior to $50 \mathrm{cGy}$. We can also see a difference of approximately -21 cGy for the TLD plan number 55, however, it was located in a transition area and this location may show results different than planned, since reliability was changed and a $1 \mathrm{~mm}$ difference in location, from actual to planned, may generate significantly discrepant results. TLD plan number 52, on the other hand, shows a difference of approximately -13 cGy between the actual dose and the planned dose, but if we evaluate it proportionally, when compared to the average dose, this difference does not exceed $6.3 \%$.

As shown in Table 2, slice 16 is the one with smaller relative standard deviations and smaller differences between planned and actual doses, when compared to other slices, precisely because planning focused on this slice. 


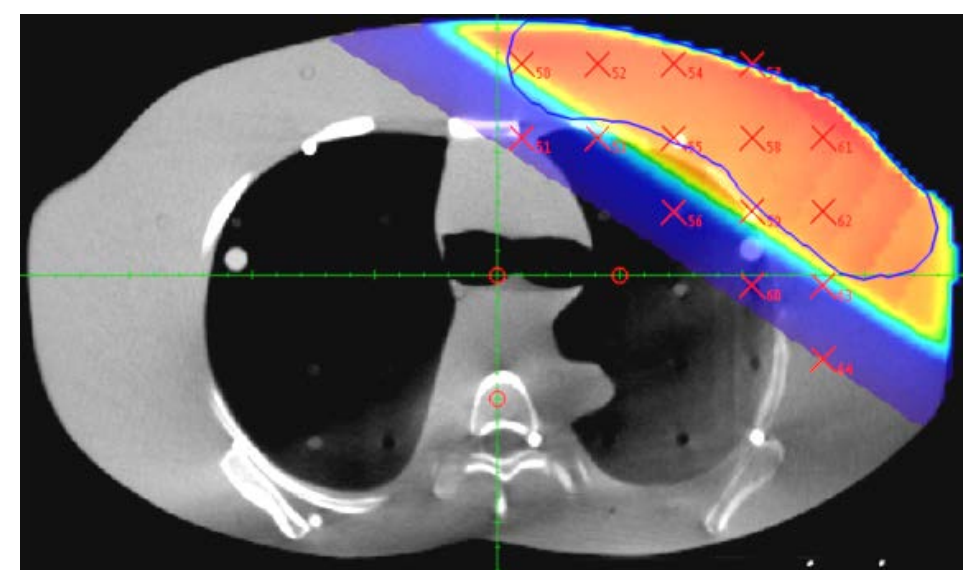

Figure 8. Distribution of TLDs in the planning system in red and experimental TLDs circled in slice 15.

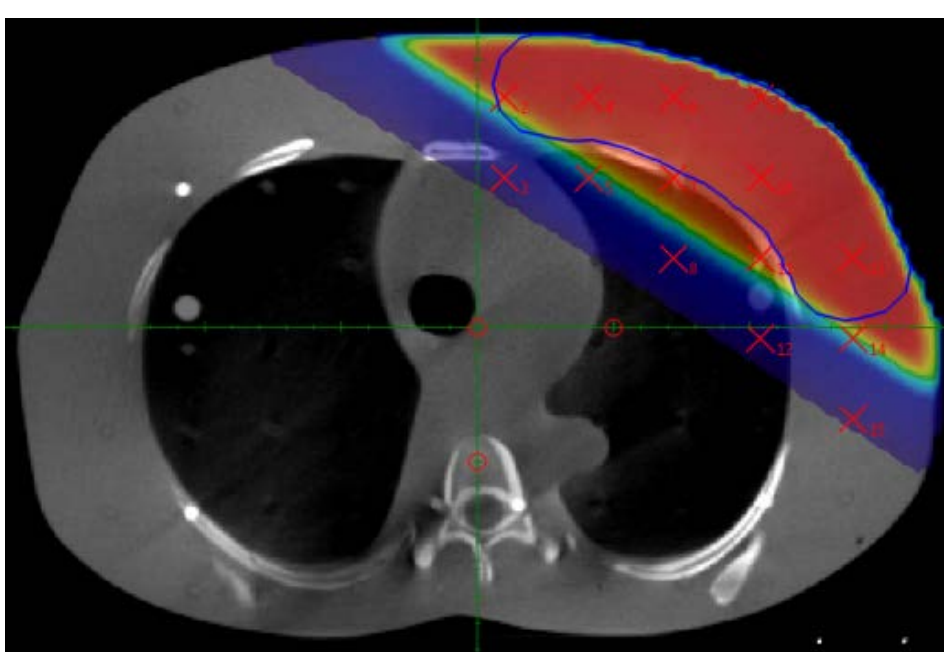

Figure 9. Distribution of TLDs in the planning system in red and experimental TLDs circled in slice 16.

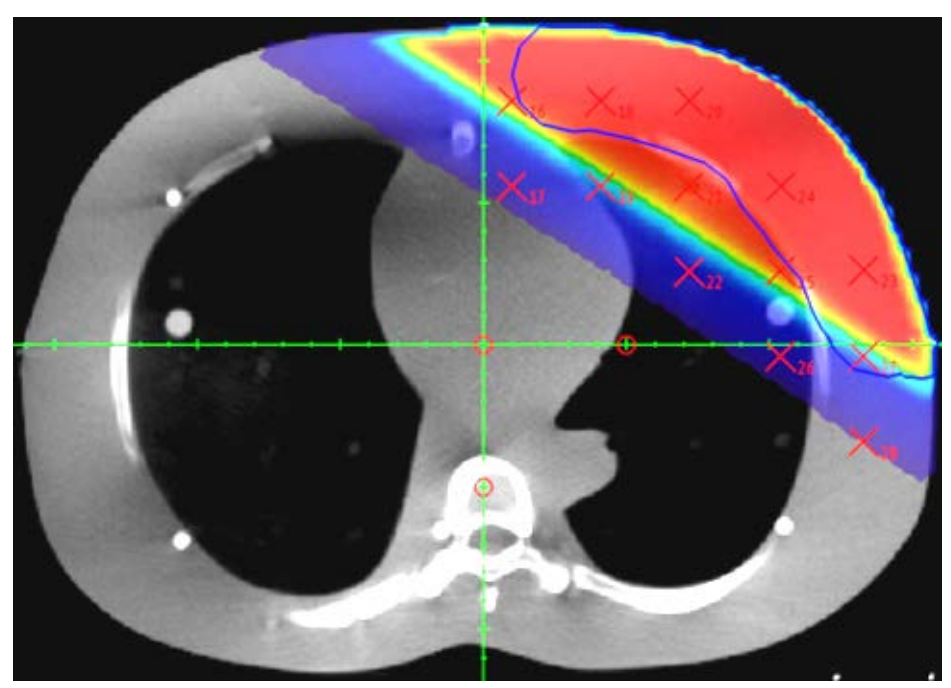

Figure 10. Distribution of TLDs in the planning system in red and experimental TLDs circled in slice 17. 


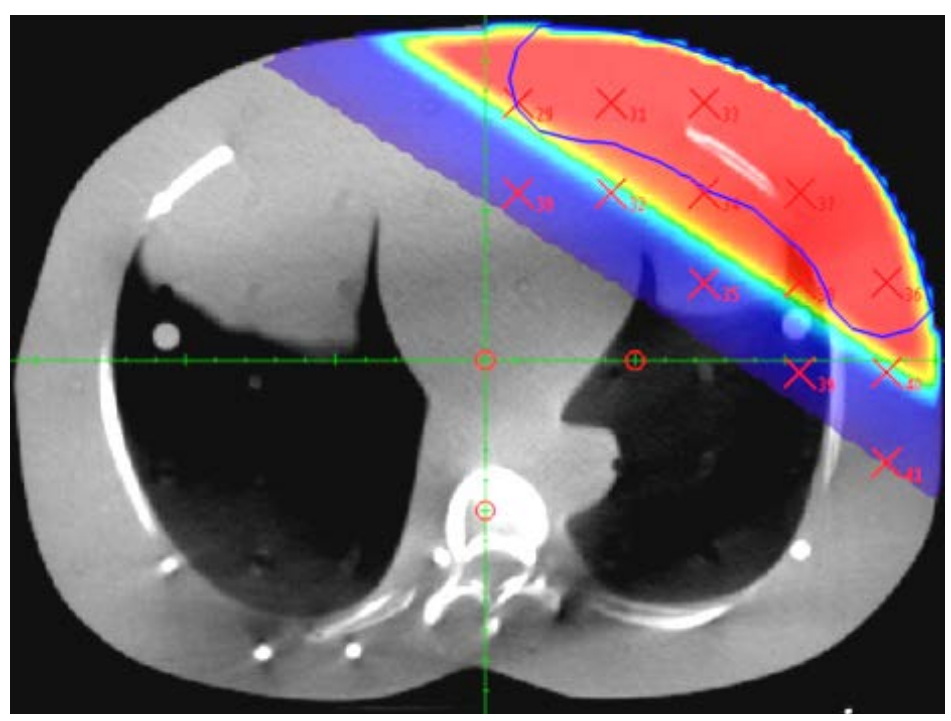

Figure 11. Distribution of TLDs in the planning system in red and experimental TLDs circled in slice 18.

Table 1. Comparison between doses absorbed by TLDs and doses planned in slice 15 .

\begin{tabular}{|c|c|c|c|c|c|c|c|c|c|c|c|}
\hline \multicolumn{12}{|c|}{ Comparison between Corrected Doses (cGy) } \\
\hline \multirow[t]{2}{*}{ TLD } & \multirow{2}{*}{$\begin{array}{l}\text { TLD } \\
\text { Plan }\end{array}$} & \multirow{2}{*}{$\begin{array}{l}\text { Planned } \\
\text { Dose }\end{array}$} & \multicolumn{3}{|c|}{ Measurement } & \multirow[t]{2}{*}{ Average } & \multirow{2}{*}{$\begin{array}{l}\text { Standard } \\
\text { Deviation }\end{array}$} & \multirow{2}{*}{$\begin{array}{c}\text { Relative } \\
\text { Standard } \\
\text { Deviation }\end{array}$} & \multirow[t]{2}{*}{ Ua } & \multirow[t]{2}{*}{ Zone $^{*}$} & \multirow{2}{*}{$\begin{array}{c}\text { Real/Planned } \\
\text { Dose }\end{array}$} \\
\hline & & & 1 & 2 & 3 & & & & & & \\
\hline $\mathrm{e} 02$ & 52 & 187.78 & 214.23 & 193.15 & 193.65 & 200.34 & 12.03 & $6 \%$ & 6.94 & $\mathrm{R}$ & -12.56 \\
\hline $\mathrm{e} 05$ & 55 & 176.35 & 194.88 & 197.26 & 199.41 & 197.19 & 2.26 & $1 \%$ & 1.31 & $\mathrm{Y}$ & -20.84 \\
\hline b01 & 58 & 181.31 & 207.40 & 194.13 & 197.78 & 199.77 & 6.85 & $4 \%$ & 3.96 & $\mathrm{R}$ & -18.46 \\
\hline n03 & 61 & 189.25 & 200.78 & 193.54 & 192.97 & 195.76 & 4.35 & $2 \%$ & 2.51 & $\mathrm{R}$ & -6.51 \\
\hline $\mathrm{d} 14$ & 63 & 42.4 & 16.59 & 18.15 & 17.96 & 17.57 & 0.85 & $2 \%$ & 0.49 & B & 24.83 \\
\hline
\end{tabular}

*R—red; Y—yellow; B-blue.

Table 2. Comparison between doses absorbed by TLDs and doses planned in slice 16 .

\begin{tabular}{|c|c|c|c|c|c|c|c|c|c|c|c|}
\hline \multicolumn{12}{|c|}{ Comparison between Corrected Doses (cGy) } \\
\hline \multirow{2}{*}{ TLD } & \multirow{2}{*}{$\begin{array}{l}\text { TLD } \\
\text { Plan }\end{array}$} & \multirow{2}{*}{$\begin{array}{l}\text { Planned } \\
\text { Dose }\end{array}$} & \multicolumn{3}{|c|}{ Measurement } & \multirow{2}{*}{ Average } & \multirow{2}{*}{$\begin{array}{l}\text { Standard } \\
\text { Deviation }\end{array}$} & \multirow{2}{*}{$\begin{array}{c}\text { Relative } \\
\text { Standard Deviation }\end{array}$} & \multirow{2}{*}{ Ua } & \multirow{2}{*}{ Zone $^{*}$} & \multirow{2}{*}{$\begin{array}{l}\text { Real/Planned } \\
\text { Dose }\end{array}$} \\
\hline & & & 1 & 2 & 3 & & & & & & \\
\hline c04 & 4 & 197.45 & 203.46 & 204.70 & 198.62 & 202.26 & 3.21 & $2 \%$ & 1.86 & $\mathrm{R}$ & -4.81 \\
\hline $\mathrm{d} 20$ & 6 & 202.47 & 218.05 & 208.29 & 198.91 & 208.41 & 9.57 & $5 \%$ & 5.53 & $\mathrm{R}$ & -5.94 \\
\hline h16 & 8 & 19.05 & 16.67 & 16.51 & 15.70 & 16.29 & 0.52 & $3 \%$ & 0.30 & B & 2.76 \\
\hline 101 & 10 & 199.45 & 204.82 & 198.26 & 193.67 & 198.92 & 5.60 & $3 \%$ & 3.24 & $\mathrm{R}$ & 0.53 \\
\hline o02 & 12 & 13.75 & 12.86 & 12.73 & 12.77 & 12.78 & 0.06 & $0 \%$ & 0.04 & B & 0.97 \\
\hline h09 & 13 & 205.29 & 206.97 & 206.22 & 213.25 & 208.81 & 3.86 & $2 \%$ & 2.23 & $\mathrm{R}$ & -3.52 \\
\hline n04 & 15 & 4.45 & 9.24 & 8.94 & 8.76 & 8.98 & 0.24 & $5 \%$ & 0.14 & B & -4.53 \\
\hline
\end{tabular}

*R—red; B—blue. 
Table 3. Comparison between doses absorbed by TLDs and doses planned in slice 17.

\begin{tabular}{|c|c|c|c|c|c|c|c|c|c|c|c|}
\hline \multicolumn{12}{|c|}{ Comparison between Corrected Doses (cGy) } \\
\hline \multirow[t]{2}{*}{ TLD } & \multirow{2}{*}{$\begin{array}{l}\text { TLD } \\
\text { Plan }\end{array}$} & \multirow{2}{*}{$\begin{array}{l}\text { Planned } \\
\text { Dose }\end{array}$} & \multicolumn{3}{|c|}{ Measurement } & \multirow[t]{2}{*}{ Average } & \multirow{2}{*}{$\begin{array}{l}\text { Standard } \\
\text { Deviation }\end{array}$} & \multirow{2}{*}{$\begin{array}{l}\text { Relative Standard } \\
\text { Deviation }\end{array}$} & \multirow[t]{2}{*}{ Ua } & \multirow[t]{2}{*}{ Zone $^{*}$} & \multirow{2}{*}{$\begin{array}{l}\text { Real/Planned } \\
\text { Dose }\end{array}$} \\
\hline & & & 1 & 2 & 3 & & & & & & \\
\hline h07 & 17 & 14.01 & 12.29 & 12.28 & 11.66 & 12.08 & 0.36 & $3 \%$ & 0.21 & B & 1.93 \\
\hline e03 & 18 & 199.73 & 200.89 & 207.14 & 207.03 & 205.02 & 3.58 & $2 \%$ & 2.06 & $\mathrm{R}$ & -5.29 \\
\hline i11 & 20 & 207.1 & 212.90 & 228.30 & 223.41 & 221.54 & 7.87 & $4 \%$ & 4.54 & $\mathrm{R}$ & -14.44 \\
\hline b15 & 21 & 190.35 & 202.00 & 204.58 & 200.47 & 202.35 & 2.07 & $1 \%$ & 1.20 & $\mathrm{R}$ & -12.00 \\
\hline n20 & 24 & 203.82 & 197.92 & 222.80 & 205.16 & 208.63 & 12.79 & $6 \%$ & 7.39 & $\mathrm{R}$ & -4.81 \\
\hline e06 & 27 & 48.2 & 23.30 & 22.65 & 24.04 & 23.33 & 0.69 & $1 \%$ & 0.40 & B & 24.87 \\
\hline
\end{tabular}

"B-blue; R—red.

Table 4. Comparison between doses absorbed by TLDs and doses planned in slice 18.

\begin{tabular}{|c|c|c|c|c|c|c|c|c|c|c|c|}
\hline \multicolumn{12}{|c|}{ Comparison between Corrected Doses (cGy) } \\
\hline \multirow[t]{2}{*}{ TLD } & \multirow{2}{*}{$\begin{array}{l}\text { TLD } \\
\text { Plan }\end{array}$} & \multirow{2}{*}{$\begin{array}{l}\text { Planned } \\
\text { Dose }\end{array}$} & \multicolumn{3}{|c|}{ Measurement } & \multirow[t]{2}{*}{ Average } & \multirow{2}{*}{$\begin{array}{l}\text { Standard } \\
\text { Deviation }\end{array}$} & \multirow{2}{*}{$\begin{array}{c}\text { Relative Standard } \\
\text { Deviation }\end{array}$} & \multirow{2}{*}{$\mathrm{Ua}$} & \multirow[t]{2}{*}{ Zone $^{*}$} & \multirow{2}{*}{$\begin{array}{c}\text { Real/Planned } \\
\text { Dose }\end{array}$} \\
\hline & & & 1 & 2 & 3 & & & & & & \\
\hline o20 & 32 & 53.29 & 25.13 & 27.67 & 27.61 & 26.80 & 1.45 & $3 \%$ & 0.84 & B & 26.49 \\
\hline o14 & 35 & 20.03 & 15.26 & 14.41 & 13.74 & 14.47 & 0.76 & $4 \%$ & 0.44 & B & 5.56 \\
\hline h08 & 37 & 204.16 & 216.37 & 228.56 & 224.50 & 223.14 & 6.21 & $3 \%$ & 3.58 & $\mathrm{R}$ & -18.98 \\
\hline $\mathrm{n} 10$ & 39 & 14.24 & 11.59 & 11.39 & 11.71 & 11.56 & 0.16 & $1 \%$ & 0.09 & B & 2.68 \\
\hline o20 & 32 & 53.29 & 25.13 & 27.67 & 27.61 & 26.80 & 1.45 & $3 \%$ & 0.84 & B & 26.49 \\
\hline
\end{tabular}

*B-blue; R-red.

Table 3 shows a difference of approximately 25 cGy for TLD plan number 27, however, this TLD has a planned dose of 48.2 cGy and the calibration curve of TLDs is also not reliable for measurements inferior to 50 cGy. We also notice a difference of approximately -15 cGy for TLD plan number 20 and of -12 cGy for TLD plan number 21, between the actual and the planned doses, but, proportionately, in relation to average doses, these differences do not exceed $-6.5 \%$.

In Table 4, there is a difference between the planned and the actual dose of up to 26 cGy, which may be associated with the location of the TLDs, which were in the blue zone, and because of the error existing in the calibration curve, for doses inferior to 50 cGy. We can also notice a difference of approximately -19 cGy for TLD plan number 37, between the actual and the planned dose; however, if we evaluate in terms of average dose, this difference means approximately $-8.5 \%$ of the measured average dose.

\section{Conclusion}

We may conclude that the volume of the male breast directly impacts the results diverging from planning. Thus, it is necessary to study and program a specific plan for the treatment of male breast cancer. The adoption of the same protocols used for the treatment of female breast cancer is not recommended.

\section{Acknowledgements}

To CAPES for the financial support that was crucial for the performance of this work. To Helio Salmon and COI-Clínicas Oncológicas Integradas team for all their help and support in the performance of irradiations. To Roberto Salomon, Paul Clivl and and the staff of SQRI/INCA-Serviço de Qualidade em Radiações Ionizantes do Instituto Nacional de Câncer, for all their help and support in carrying out the readings of thermoluminescent dosimeters. 


\section{References}

[1] Paiva, S.M.M. (2006) Avaliação da qualidade de vida de pacientes oncológicos em tratamento quimioterápico adjuvante. Dissertação, Ribeirão Preto, 111 p.

[2] Hill, T.D., Khamis, H. J., Tyczynski, J.E. and Berkel, H.J. (2005) Comparison of Male and Female Breast Cancer Incidence Trends, Tumor Characteristics, and Survival. Annals of Epidemiology, 15, 773-780. http://dx.doi.org/10.1016/j.annepidem.2005.01.001

[3] Giordano, S.H. (2005) A Review of the Diagnosis and Management of Male Breast Cancer. Oncologist, 7, $471-479$. http://dx.doi.org/10.1634/theoncologist.10-7-471

[4] Carmalt, H.L., Mann, L.J., Kennedy, C.W., Fletcher, J.M. and Gillet, D.J. (1998) Carcinoma of the Male Breast: A Review and Recommendations for Management. ANZ Journal of Surgery, 68, 712-715. http://dx.doi.org/10.1111/j.1445-2197.1998.tb04657.x

[5] Leme, L.H.S. and Souza, G.A. (2006) Câncer de mama em homens: Aspectos epidemiológicos, clínicos e terapêuticos. Revista de Ciências Médicas, 15, 391-398.

[6] Izewska, J. and Rajan, G. (2005) Chapter 3: Radiation Dosimeters. In: Podgorsak, E.B., Ed., Radiation Oncology Physics: A Handbook for Teachers and Students, International Atomic Energy Agency-IAEA, Vienna.

[7] Da Rosa, L.A.R. (2001) Dosimetria Termoluminescente Aplicada à Física Médica, Instituto de Radioproteção e Dosimetria-CNEN, Rio de Janeiro.

[8] ICRU (1989) International Commission on Radiation Units and Measurements. Tissue substitutes in radiation dosimetry and measurement, Report 44, Bethesda.

[9] Guimarães, N.A. and Crispim, V.R. (2013) Dosimetric Evaluation in Teletherapy to Treatment of Male Breast. International Nuclear Atlantics Conference, Pernambuco. 
Scientific Research Publishing (SCIRP) is one of the largest Open Access journal publishers. It is currently publishing more than 200 open access, online, peer-reviewed journals covering a wide range of academic disciplines. SCIRP serves the worldwide academic communities and contributes to the progress and application of science with its publication.

Other selected journals from SCIRP are listed as below. Submit your manuscript to us via either submit@scirp.org or Online Submission Portal.
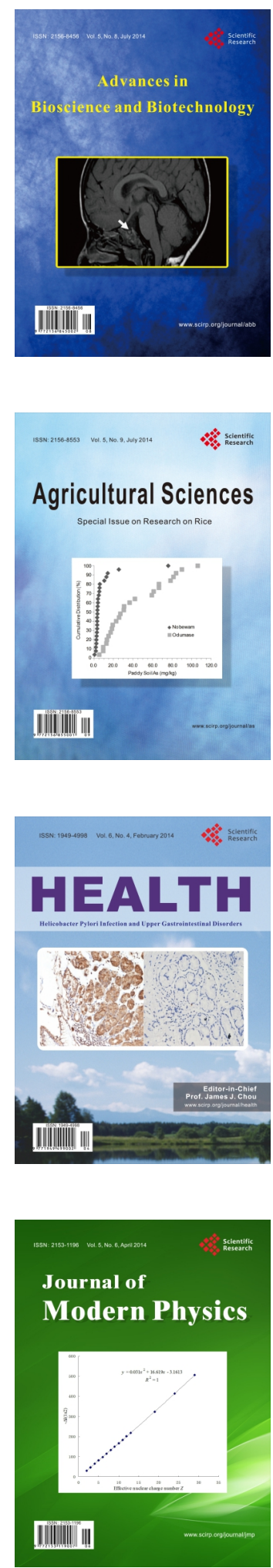
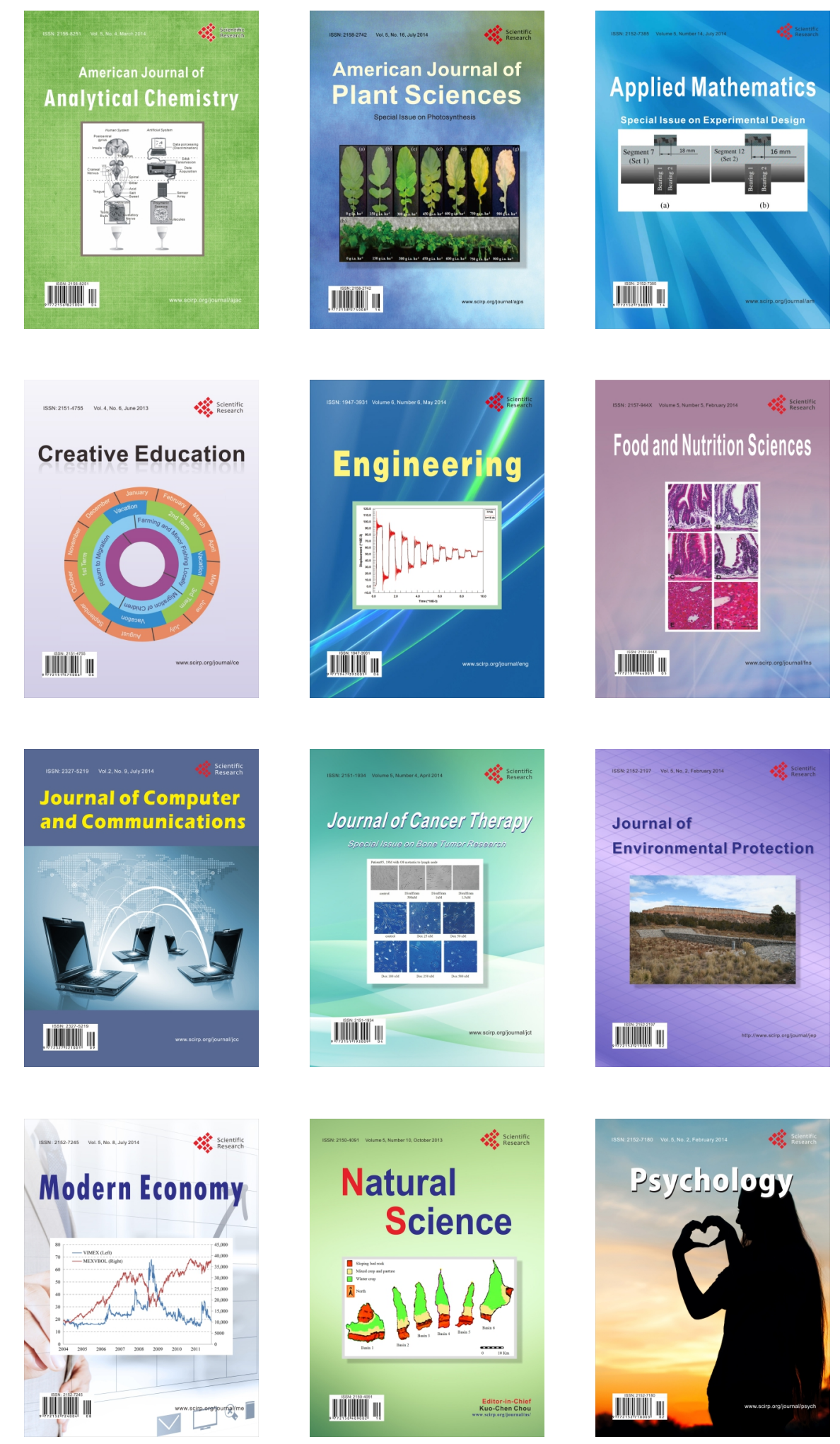